\title{
AS PAISAGENS DO MUNICÍPIO DE PINHAIS (PARANÁ/BRASIL): UMA ABORDAGEM SEGUNDO O CONCEITO DE HEMEROBIA
}

\author{
Eduardo Liberti \\ Mestrando em Geografia na linha de pesquisa Paisagem e Análise Ambiental pelo Programa de Pós-Graduação \\ em Geografia pela Universidade Federal do Paraná - UFPR \\ eduardoliberti@hotmail.com \\ Henrique Reisdorfer Leite \\ Mestrando em Geografia na linha de pesquisa Paisagem e Análise Ambiental pelo Programa de Pós-Graduação \\ em Geografia pela Universidade Federal do Paraná - UFPR \\ reisdorferleite@gmail.com \\ Maria Consuelo da Silva \\ Licenciada e Bacharel em Geografia pela Universidade Federal do Paraná - UFPR \\ maria.consuelo@hotmail.com \\ João Carlos Nucci \\ Professor Dr. do Departamento de Geografia e do Programa de Pós-Graduação em Geografia da Universidade \\ Federal do Paraná - UFPR \\ icnucci@gmail.com
}

\begin{abstract}
RESUMO
Foram identificadas, classificadas e mapeadas as paisagens do município de Pinhais/Paraná de acordo com o conceito de Hemerobia, que pode ser compreendido como a dependência energética e tecnológica que as paisagens possuem para sua manutenção. Foram utilizadas imagens de satélite disponibilizadas pelo Google Earth, ano 2017, para identificar as unidades de paisagem (UP's) da área de estudo. A classificação da hemerobia das paisagens foi realizada com adaptações no método proposto por Belem e Nucci (2011), sendo identificadas e delimitadas 5 classes de hemerobia. O mapeamento das UP's, conforme a dependência energética e tecnológica, foi realizado no software ArcGIS 10.3, módulo Arcmap. Dentre os resultados alcançados, evidenciou-se que quase $41 \%$ da área de estudo possui hemerobia máxima, sendo esta a pior classe relativa, estando a mesma concentrada nas partes oeste e sudoeste do município de Pinhais, caracterizadas por usos residenciais, comerciais e industriais. As melhores classes de hemerobia (mínima e baixa) representam quase $43 \%$ da área do município, sendo a cobertura da terra representada por vegetação natural e/ou plantada, áreas de campo e/ou pasto, rios e parte da represa do Iraí. Os resultados obtidos com o método utilizado apresentam-se como uma importante ferramenta para compreender a dinâmica das paisagens urbanas, colaborando para o planejamento, gestão e ordenamento das cidades.
\end{abstract}

Palavras-chave: Unidades de paisagem. Ecologia urbana. Hemerobia. Pinhais.

\section{THE LANDSCAPES IN THE MUNICIPALITY OF PINHAIS (PARANÁ/BRAZIL): AN APPROACH FOLLOWING THE CONCEPT OF HEMEROBY}

\begin{abstract}
The landscapes of the Municipality of Pinhais (State of Paraná/Brazil) were identified, classified and mapped according to the concept of Hemeroby, which comprises the technological and energetic dependency the landscapes own for their own maintenance. . To achieve that, satellite images from the year of 2017 available through Google Earth were used in order to identify the Landscape Units of the study area. The mapping was done in the scales of $1: 40,000$ to $1: 50,000$ using the software ArcGIS 10.3, Arcmap module. Five classes of landscape hemeroby were identified and delimited through adaptations made to the method proposed by Belem and Nucci (2011). Amongst the attained results, it was evidenced that approximately $41 \%$ of the study area had the maximum hemeroby, this being relatively the worst class. The identified area occupies the western and southwestern parts
\end{abstract}

Caminhos de Geografia $\quad$ Uberlândia $\quad$ v. 20, n. $72 \quad$ Dez/2019 $\quad$ p. 189-201 Página 189


of the municipality, characterized by residential, commercial and industrial uses. The better classes of hemeroby (minimum and low) represent almost $43 \%$ of the municipality. Land uses in such area are characterized by natural and/or planted vegetation; crops; open fields; rivers and a part of the Iraí reservoir. The reached results with the proposed method present themselves as an important tool to comprehend the dynamic of urban landscapes, collaborating with planning and management of cities.

Keywords: Landscape unites. Urban ecology. Hemeroby. Pinhais.

\section{INTRODUÇÃO}

O processo de urbanização promove transformações que causam significativas e, por vezes, irreversíveis mudanças na estrutura da paisagem, alterando, consequentemente, seu funcionamento/dinâmica.

As dinâmicas das diferentes paisagens existentes nas cidades podem fornecer uma série de benefícios, como também limitações, para o uso e a ocupação humana, ou seja, as paisagens podem e devem ser caracterizadas por sua estrutura e dinâmica visando evidenciar as suas potencialidades (limites e aptidões).

Santos (2004, p. 28) afirma que "no planejamento ambiental deve-se levar em consideração a potencialidade do meio, ou seja, seus limites (fragilidade) e aptidões. (...) as restrições do meio devem ter prioridade sobre as demandas sociais ou econômicas".. E complementa que "Se ambiental, o planejamento deve promover e garantir a proteção aos sistemas naturais. Porém, nem sempre essa reflexão é feita, gerando muitas divergências" (SANTOS, 2004, p. 37).

Sobre os benefícios ou aptidões das paisagens, pode-se resgatar o termo "funções da natureza" utilizado por De Groot (1992), como sendo a capacidade dos processos e componentes naturais de fornecerem benefícios e serviços que satisfaçam, direta e/ou indiretamente, às necessidades humanas (fisiológicas e psicológicas).

Mesmo estando mais ligadas aos ecossistemas naturais, as funções da natureza conforme aponta De Groot (1992) também podem ser consideradas nas paisagens urbanizadas. A capacidade dos solos permeáveis favorecendo a infiltração das águas pluviais e colaborando para a regulação do ciclo hidrológico e a cobertura vegetal beneficiando o conforto térmico e a redução da ilha de calor, são exemplos de funções da natureza na cidade.

Quando as funções da natureza são desprezadas e há a necessidade de correção dos impactos ambientais negativos, geralmente apela-se para o emprego demasiado de energia e de recursos tecnológicos nas paisagens, que se tornariam, de acordo com Nucci et al. (2016):

paisagens cujo funcionamento depende de fontes de energia que provocam danos ao meio ambiente ou à saúde dos seres humanos, geralmente gerando poluição, como as derivadas do petróleo (gasolina, diesel e querosene de aviação), carvão mineral e vegetal, energia nuclear e gás natural e, também, dependentes de tecnologias (conjunto de instrumentos, métodos e técnicas) que causem poluição ambiental (...). (NUCCl et al., 2016, p. 60)

Então, pode-se afirmar que as modificações antrópicas na paisagem, sobretudo urbanas, por vezes, não consideram as leis físicas que regem a dinâmica natural de manutenção e funcionamento da natureza (MATEO-RODRIGUES et al., 2007; SILVA e NUCCI 2016), demandando cada vez mais a utilização de energia e tecnologia poluidoras à serviço dos seres humanos, exatamente o inverso há muito tempo recomendado por McHarg (1971), ou seja, o de se buscar projetar e planejar com a natureza e não contra ela. Ingegnoli (2002) afirma que não se deve ir contra as leis da natureza, apostando apenas na tecnologia para a solução dos problemas. Para Cavalheiro (2009) a alternativa mais interessante para a urbanização é primeiro ver o que a paisagem pode oferecer no que tange a sua auto regeneração e somente depois verificar quais as tecnologias a serem utilizadas.

Um termo que sintetiza essas questões e que vem sendo adaptado e utilizado na avaliação da dependência energética e tecnológica das paisagens urbanizadas é o de hemerobia (BELEM e $\mathrm{NUCCI}, 2011$ ). Porém, em sua origem, esse termo apresentava outro significado, tendo sido aplicado

Caminhos de Geografia $\quad$ Uberlândia $\quad$ v. 20, n. $72 \quad$ Dez/2019 $\quad$ p. 189-201 Página 190


em paisagens não urbanas. Para Walz e Stein (2014), o conceito de hemerobia foi desenvolvido originalmente para avaliar os impactos causados pelo ser humano na fauna e flora (WALZ e STEIN, 2014).

O termo hemerobia, do grego hémeros (domesticado, cultivado) e bíos (vida), foi utilizado pela primeira vez em 1955 pelo botânico Jalas (TROPPMAIR, 1989; WALZ e STEIN, 2014). Mais tarde o conceito foi utilizado por Sukopp (1972) significando, graus de naturalidade, propondo classificações das paisagens em naturais, seminaturais, antroponaturais e antropizadas, sendo a hemerobia entendida como uma medida integrativa dos impactos das intervenções humanas nos ecossistemas (WALZ e STEIN, 2014).

Para Walz e Stein (2014), os impactos humanos nas paisagens dos países, estados, municípios, bairros, etc., podem ser monitorados examinando-se a tendência evolutiva dos índices de hemerobia. Naveh e Lieberman (1984) e Zoneveld e Forman (1990) ensinam que a paisagem pode ser abordada por quatro aspectos: aspecto visual (a paisagem como cenário); aspecto corológico (heterogeneidade horizontal - espacialização, cartografia; estudo das relações paisagem-ecologia em um mosaico de ecótopos); aspecto topológico (heterogeneidade vertical - a paisagem como ecossistema, formado por todos os elementos da Terra - físicos, biológicos e noosféricos [produzido pela mente humana]) e o aspecto evolutivo (tempo). Panizza (2014) expõe que muitos estudos da paisagem registram um momento, uma marca, não mostrando, por conseguinte, a dinâmica nem sua evolução, assim, segundo a autora, a apreensão das transformações paisagísticas só pode ser feita pela análise diacrônica. Um estudo da evolução da paisagem com utilização do conceito de hemerobia pode ser encontrado em Nucci et al. (2016).

Ainda sobre a evolução do conceito de hemerobia, Haber (1990), propõe a classificação dos ecossistemas em Bio-ecossistemas e Tecno-ecossistemas, considerando a necessidades de tecnologia e energia para o funcionamento dos ecossistemas. Belem e Nucci (2011), baseando-se em Haber (1990), relacionaram o conceito de hemerobia com a dependência energética e tecnológica que as paisagens possuem para sua manutenção, destacando-se trabalhos que tiveram como objetivo a aplicação e discussão desta proposta, como, por exemplo, Belem e Nucci (2014), Barbara et al. (2014), Silva e Nucci (2016), Nucci et al. (2016), dentre outros. Uma revisão mais completa sobre as definições e aplicações do conceito de hemerobia pode ser encontrada em Belem e Nucci (2011).

Até o presente momento, os trabalhos que se utilizaram do método proposto por Belem e Nucci (2011), como nos casos supracitados, o fizeram em escala de detalhe, entre 1:5.000 e 1:10.000, com aplicação no recorte espacial referente à bairros urbanos.

Com base nessas questões, a pesquisa teve como objetivo verificar a aplicabilidade de tal proposta em uma escala menor, entre 1:40.000 e 1:50.000, abrangendo o recorte espacial de todo um município, no caso o de Pinhais/PR. A escolha desse recorte espacial justifica-se, dentre outros, pela relevância que o município apresenta no contexto dos seus recursos hídricos, visto que abriga importantes mananciais responsáveis pelo abastecimento de água de Curitiba, capital do estado do Paraná, e sua Região Metropolitana, além de apresentar uma grande variedade de paisagens, denotando-se oportuno para o desenvolvimento da presente pesquisa.

A utilização do conceito de Hemerobia para compreender e verificar as demandas de energia e tecnologia necessárias para a manutenção das paisagens urbanizadas apresenta-se como uma importante ferramenta para o planejamento e ordenamento das cidades.

\section{PROCEDIMENTOS METODOLÓGICOS}

O município de Pinhais, pertencente ao Estado do Paraná, possui uma área aproximada de 61,137 $\mathrm{km}^{2}$ e faz parte da Região Metropolitana de Curitiba (RMC) (FIGURA 1). O êxodo rural, a partir da década de 70 , fez com que o fluxo populacional crescesse significativamente na RMC, tornando Pinhais um dos 14 municipios mais populosos do estado. Em 2010 o contingente populacional era de 117.008 habitantes, com estimativas de 129.445 para o ano de 2017 (IBGE, 2010). Já o relevo pode ser considerado plano, com partes levemente onduladas, planícies de várzeas e inundações devido a proximidade com a Serra do Mar o que, associado ao alto índice de urbanização do município, agrava os riscos de enchentes (PINHAIS, 2010). 
Figura 1 - Mapa de localização do município de Pinhais/PR.

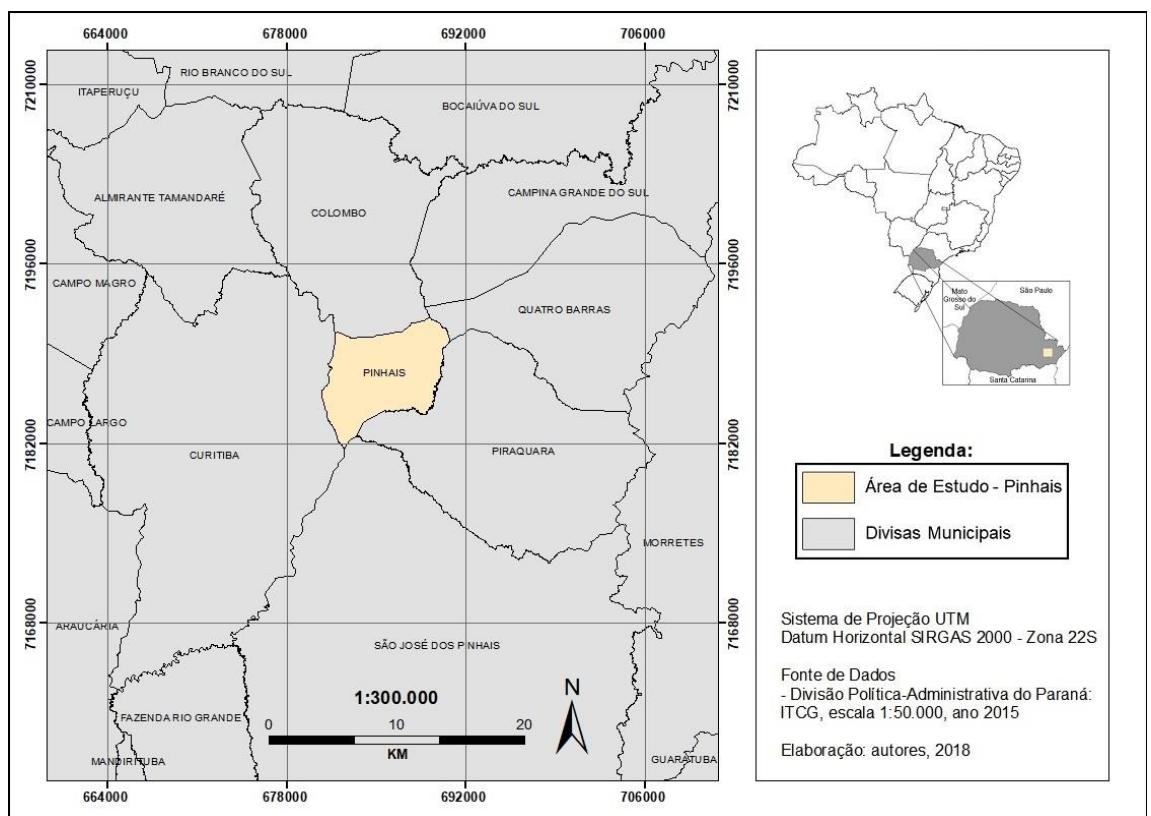

Fonte - autores, 2018.

De acordo com o Plano de Habitação e Regulação Fundiária de Pinhais (PINHAIS, 2010), o município era recoberto originalmente pelo Bioma Mata Atlântica, com formações características da Floresta Ombrófila Mista Aluvial e Montana e de Campos. A Floresta Ombrófila Mista Aluvial, de maior representatividade nessa região, tem formação ribeirinha em terrenos aluviais junto aos corpos hídricos. Outra formação característica do local são os Campos Naturais, predominante em áreas planas que foram e são fortemente afetadas pelas atividades agropecuárias.

Pinhais se encontra na bacia hidrográfica do Alto Iguaçu, compreendendo parte dequatro subbacias, sendo elas: do rio Atuba, do rio Palmital, do rio do Meio e do rio Iraí, além de parte da área de contribuição direta do rio Iguaçu (FIGURA 2). O município apresenta altos riscos de inundação e enchentes devido ao alto grau de urbanização, principalmente nas planícies de inundação dos rios Atuba, Palmital e Iraí (CHEPAK, 2008; PINHAIS, 2010).

Figura 2 - Sub-bacias presentes no município de Pinhais/PR.

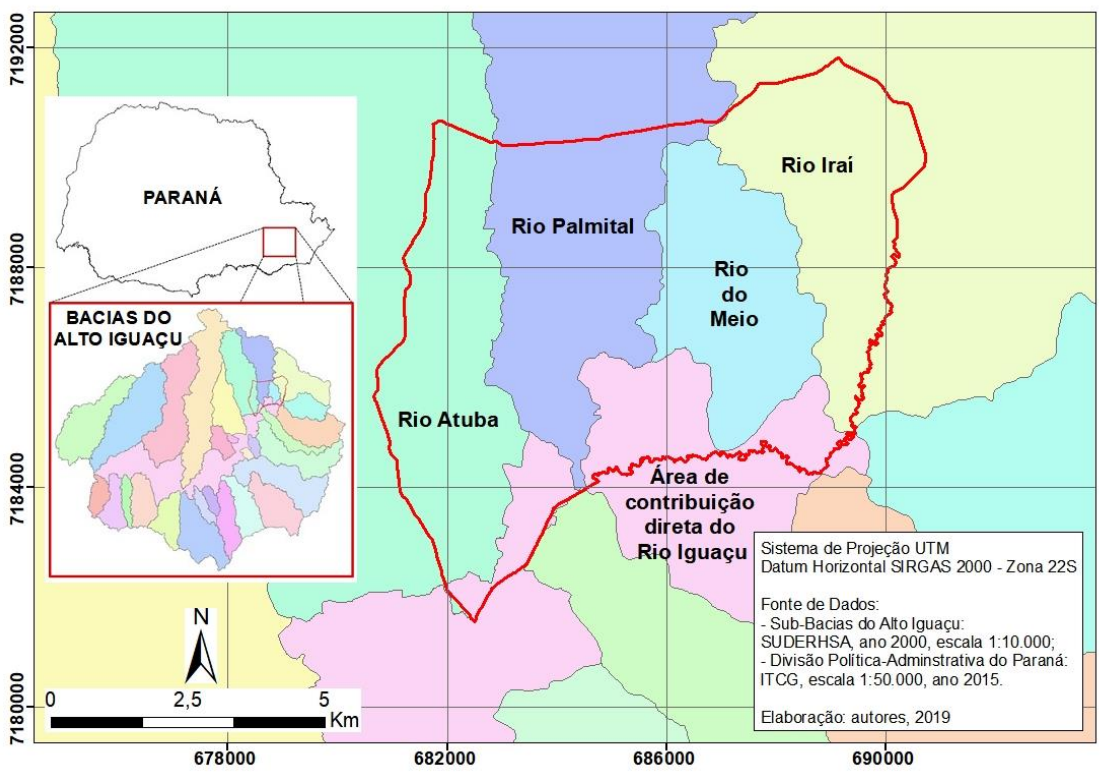

Fonte - autores, 2019. 
Devido ao potencial hídrico do município e sua importância para o abastecimento da RMC, foi criada com base no Decreto estadual ํㅜ 1753/96, a Área de Proteção Ambiental (APA) do rio Iraí, que tem como principal objetivo proteger a qualidade da água do reservatório do rio Iraí e os mananciais que abastecem Curitiba e RMC (PARANÁ, 1996). Apesar da represa do Iraí se localizar fora dos limites do município, boa parte da sua região nordeste pertence a APA do rio Iraí.

$\mathrm{Na}$ figura 3 é possível observar de maneira esquemática as etapas referentes aos procedimentos metodológicos realizados nesta pesquisa.

Figura 3 - Fluxograma dos procedimentos metodológicos.

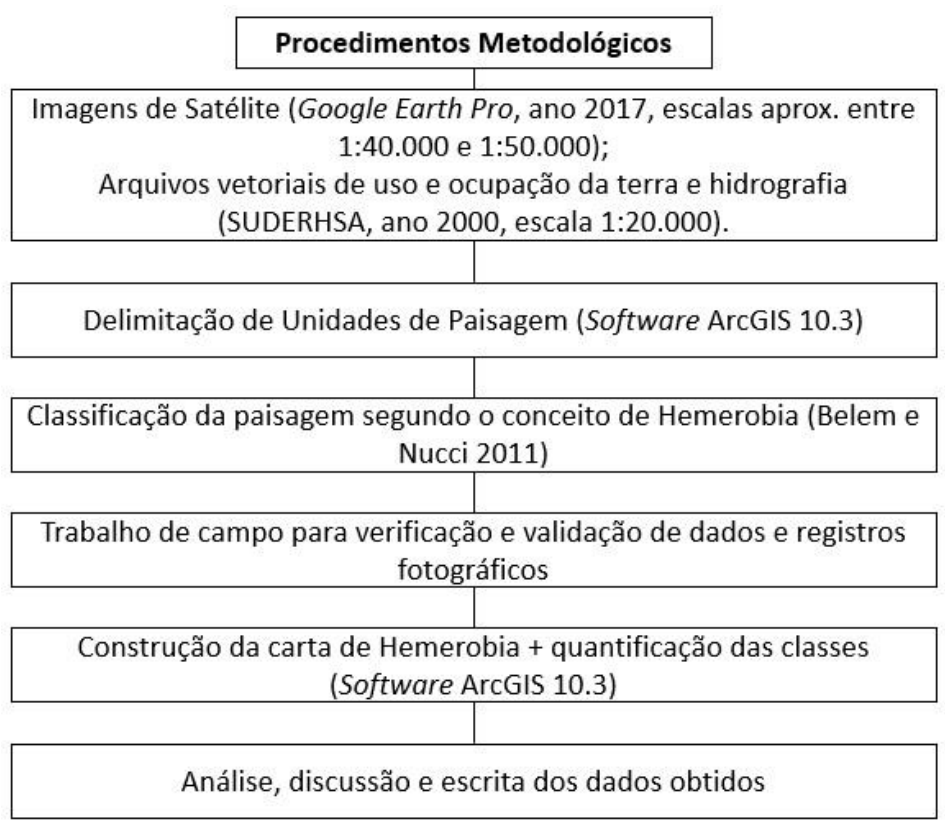

Fonte - autores, 2019.

Utilizou-se o método proposto por Belem e Nucci (2011), no qual são identificadas, por meio da interpretação visual de imagens de satélite, unidades de paisagens (UP's), classificando-as de acordo com sua dependência energética e tecnológica, variando de paisagens com o máximo até o mínimo de hemerobia. Cabe destacar que esse método é uma proposta para avaliação da hemerobia de áreas urbanas e em escalas maiores (1:5.000 - 1:10.000), visando obter um grau maior de detalhamento sobre os elementos da paisagem.

A identificação e delimitação das UP's foi realizada por meio da interpretação visual, considerando a homogeneidade da cobertura da terra, utilizando-se como base as imagens orbitais georreferenciadas do Google Earth Pro, ano de 2017, em escalas aproximadas entre 1:40.000 1:50.000. O mapeamento das UP's foi realizado com o software ArcGIS 10.3, módulo Arcmap, utilizando-se arquivos vetoriais referentes ao uso e ocupação da terra e hidrografia, escala 1:20.000, ano 2000, disponibilizado pelo Instituto das Águas do Paraná (SUDERHSA) e limites municipais e rodovias, escala 1:15.000, ano 2010, disponibilizado pelo Instituto de Terra, Cartografia e Geologia do Paraná (ITCG).

No método proposto por Belem e Nucci (2011), a identificação dos graus de hemerobia não é absoluta, variando de mínima, muito baixa, baixa, média, alta, muito alta até a máxima. Neste sentido, a hemerobia depende dos tipos de paisagens encontradas no local estudado, tratando-se de uma avaliação relativa por meio da comparação entre as diferentes paisagens.

$\mathrm{Na}$ figura 4 é possível observar a chave de classificação contendo os graus de dependência energética e tecnológica (hemerobia) propostos por Belem e Nucci (2011), organizada de modo comparativo entre as diferentes paisagens identificadas na área de estudo. 
Figura 4 - Chave de classificação da hemerobia do município de Pinhais/PR.

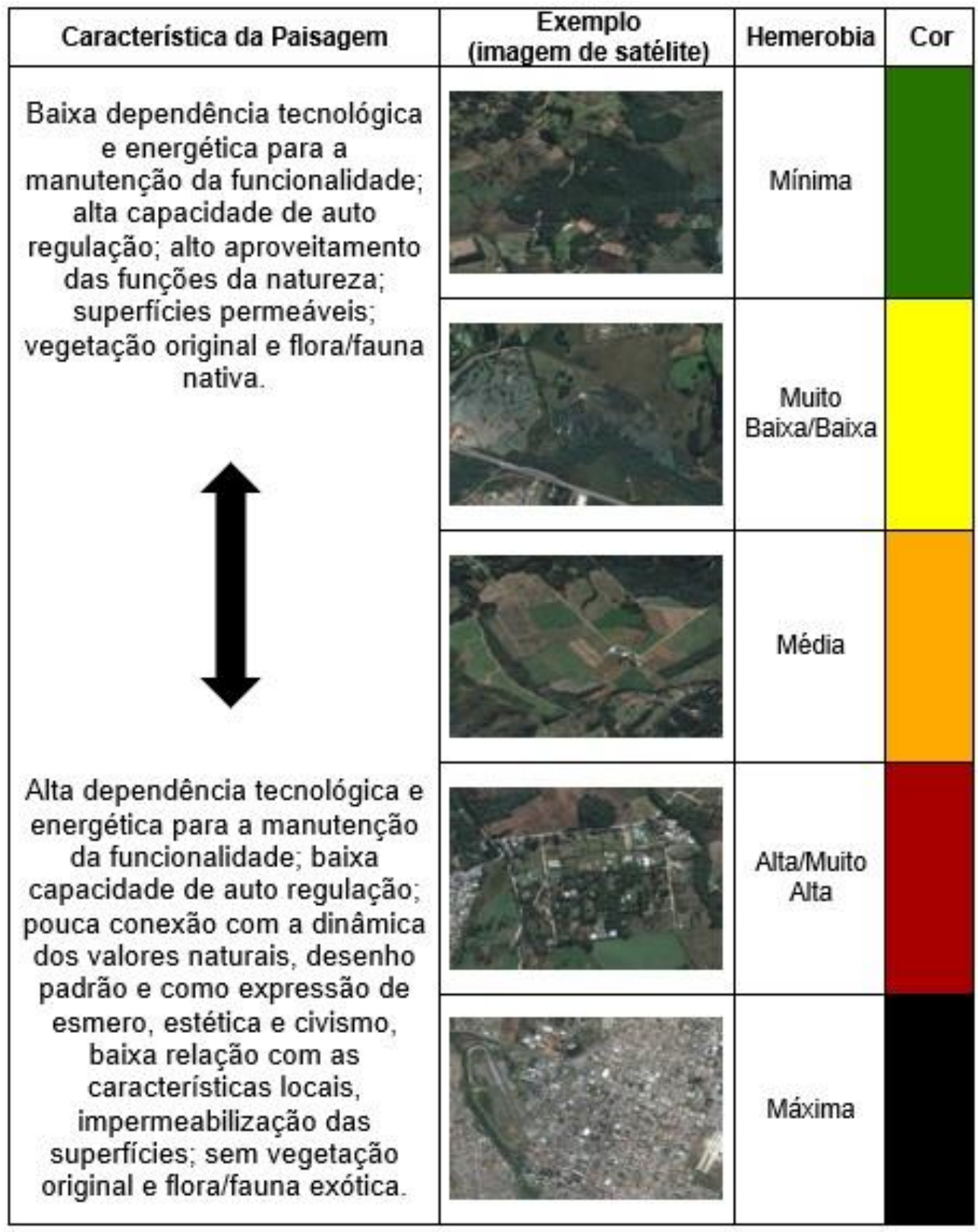

Fonte - Belem e Nucci (2011), adaptado pelos autores, 2018.

Devido a escala utilizada para a classificação da hemerobia do município de Pinhais não apresentar o nível de detalhamento sugerido na proposta do método utilizado, foi necessário realizar adaptações, sendo assim, agrupou-se as classes de hemerobia "baixa e muito baixa" em uma mesma categoria, o mesmo ocorreu com as classes "alta e muito alta".

Considerou-se as classes de menor hemerobia aquelas com paisagens na qual as mudanças na vegetação natural apresentam-se imperceptíveis por meio da interpretação visual. Por outro lado, as classes com a maior hemerobia são representadas por paisagens que apresentam grandes e adensadas edificações e com o solo bastante impermeabilizado.

\section{RESULTADOS E DISCUSSÕES}

Como um dos resultados obteve-se a carta de hemerobia do município de Pinhais, que pode ser observada na figura 5.

Caminhos de Geografia $\quad$ Uberlândia $\quad$ v. 20, n. $72 \quad$ Dez/2019 $\quad$ p. 189-201 Página 194




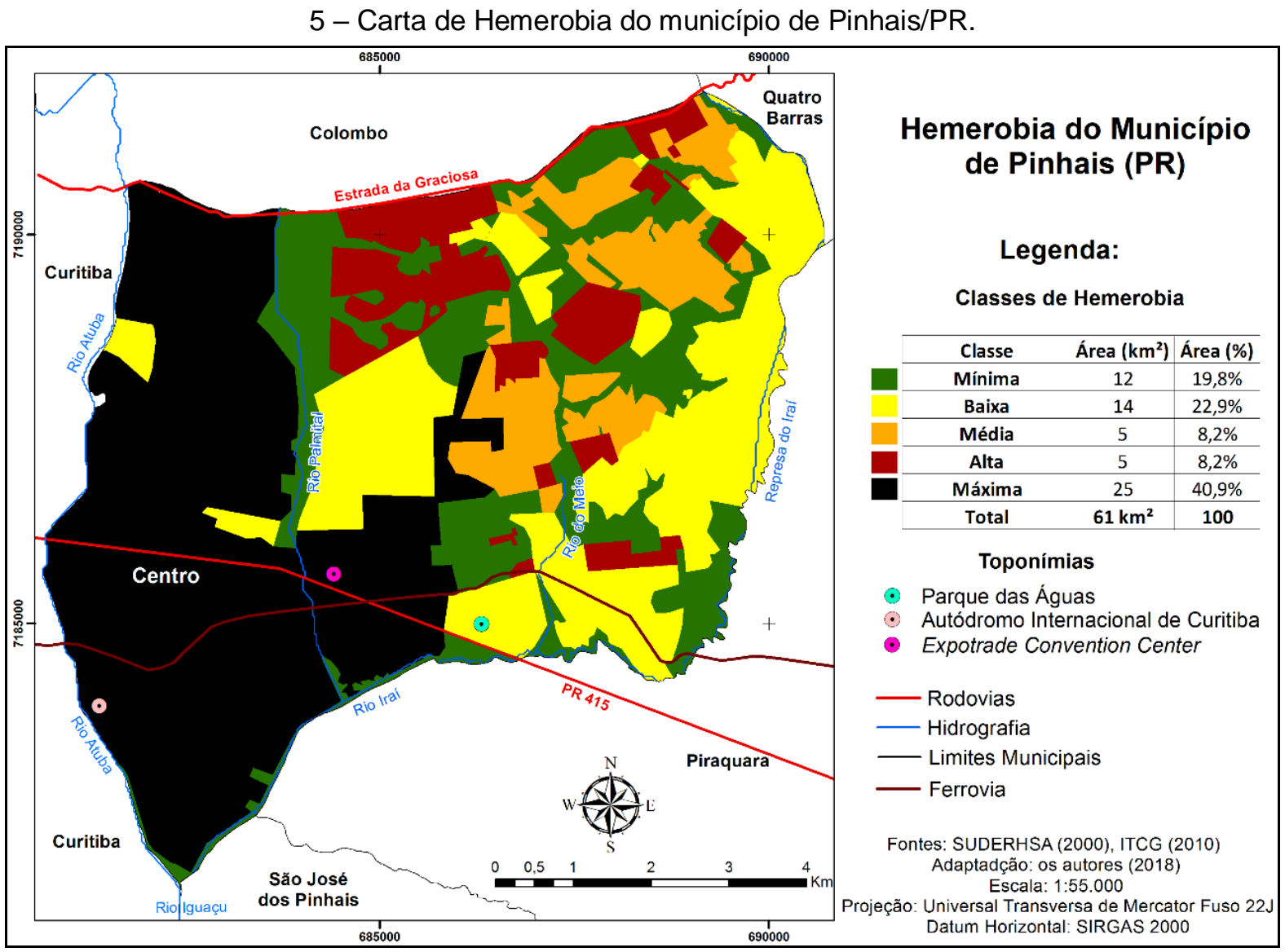

Fonte - autores, 2018.

Com base na figura 5 pode-se observar que mais de $40 \%$ da área de estudo apresenta alto grau de dependência energética e tecnológica para a manutenção da funcionalidade das funções ecológicas da paisagem. No outro extremo à essa classe, correspondendo a melhor hemerobia, está a de paisagem com dependência energética e tecnológica mínima, representando pouco menos de $20 \%$ do total da área do município de Pinhais.

Constata-se que a pior classe de hemerobia, ou seja, a máxima, concentra-se nas partes oeste e sudoeste da área de estudo, fazendo limite com o município de Curitiba, configurando-se em um processo de conurbação que, de acordo com o IBGE (2016), constitui-se como a união de tecidos urbanos, nas quais cidades vizinhas estabelecem fortes vínculos político-admistrativos e socioeconômicos entre si. Uma constatação importante que se faz em relação a hemerobia máxima refere-se ao limite das UP's, na qual a mesma faz fronteira com as classes de dependência energética e tecnológica mínima e baixa, na direção oeste-leste, podendo indicar áreas que mereçam atenção dos órgãos oficiais e da própria população quanto ao processo de expansão da urbanização.

\section{Paisagem com Hemerobia Mínima}

A hemerobia mínima encontra-se fragmentada entre as partes norte, centro e sudeste do município e é composta por áreas de vegetação natural e/ou plantadas e representam $12 \mathrm{~km}^{2}$ do total da área mapeada, ou seja 19,8\% da área de estudo. Tem como expoentes as áreas de reflorestamento (pinus e eucaliptos), atividades muito comuns na região e com diversificados exemplares da vegetação original, correspondente à Floresta Ombrófila Mista, como, por exemplo, a Araucária (Araucaria angustifolia) Pinheiro Bravo (Podocarpus lambertil), Cataia (Drymis brasiliensis), dentre outras (FIGURA 6) (CHEPAK, 2008). 
Figura 6 - Hemerobia mínima, correspondente às áreas de vegetação natural e/ou plantadas do município de Pinhais/PR.

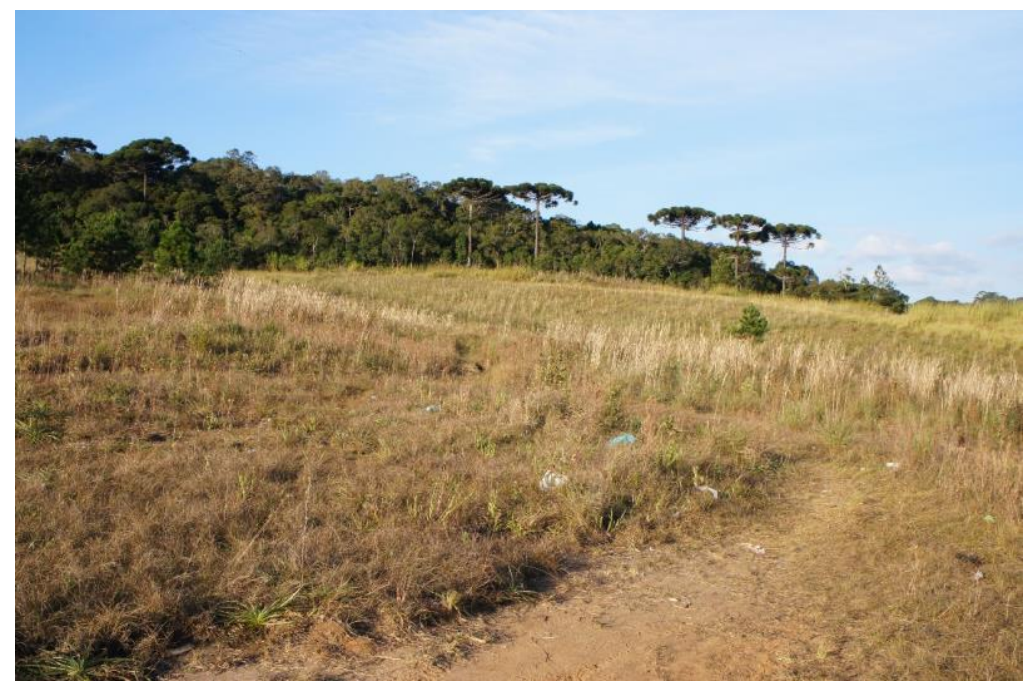

Fonte - autores, 2018

Algumas áreas classificadas com hemerobia mínima à norte e sudeste correspondem à Zona de Restrição à Ocupação (ZRO), referentes a Lei № 1.233/2011, que dispõe sobre o Zoneamento, o uso e a ocupação do solo no município de Pinhais.

Com baixa impermeabilização do solo e alta conservação de importantes espécies vegetais, as funções ecológicas são mantidas e a auto regulação é garantida, dispensando qualquer necessidade de intervenção humana.

\section{Paisagem com Hemerobia Baixa}

Essa classe representa $14 \mathrm{~km}^{2}$, ou $22,9 \%$ da área de estudo. O uso e a cobertura da terra são constituídos por áreas de campo e/ou pasto e pelos rios e parte da represa do Iraí. São áreas provenientes da formação original de Campos Naturais, que eram constituídas por vegetação herbácea, capões e matas de galeria. Essas áreas sofreram intensivas intervenções antrópicas, como, por exemplo, a incorporação de espécies exóticas na flora, o avanço da agropecuária e da mancha urbana (FIGURA 7). A área que se estende desde a represa do Iraí até o Parque das Águas é a mais bem conservada e engloba resquícios mínimos da Floresta Ombrófila Mista Aluvial (CHEPAK, 2008).

Figura 7 - Hemerobia baixa, correspondente às áreas de campo e/ou pastagem do município de Pinhais/PR

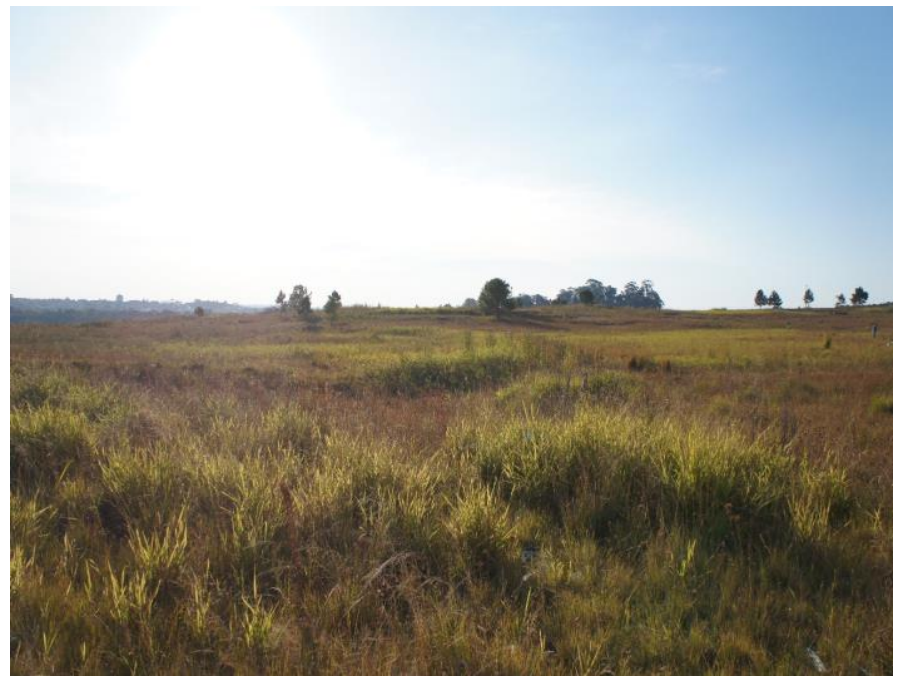

Fonte - autores, 2018. 
Mesmo com um índice alto de perda de vegetação nativa considerou-se a hemerobia como baixa, devido a sua reduzida dependência de energia e a função de proteção que a vegetação exerce sobre o solo, reduzindo impactos como o da erosão e contribuindo para o conforto térmico.

Os recursos hídricos estão presentes nesta classe por apresentar, no caso da represa do Iraí, alto grau de eutrofização, como apontado por Franz et al. (2007) com base em estudos empíricos e de modelagem, e pelas constantes ações de desassoreamento de importantes rios que cortam o município, como, por exemplo, os rios Iraí, Atuba, Palmital e do Meio (Pinhais, 2014), ocasionando dependência tecnológica para a manutenção dos mesmos (FIGURA 8).

Figura 8 - Limpeza e desassoreamento do rio Atuba no município de Pinhais/PR.

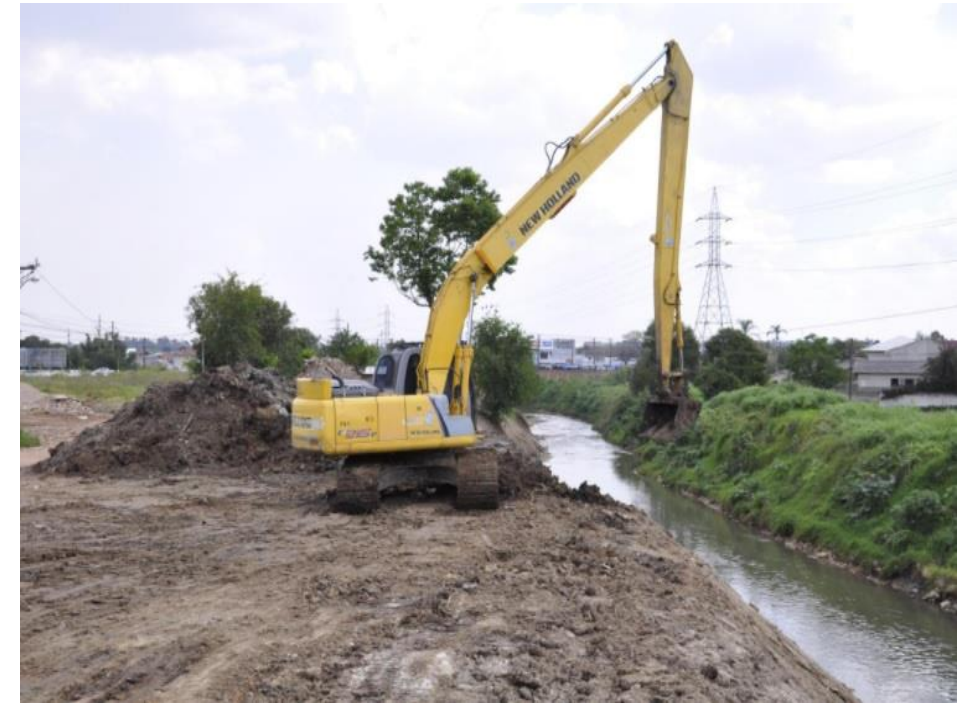

Fonte - Pinhais (2014).

\section{Paisagem com Hemerobia Média}

A classe de hemerobia média representa $5 \mathrm{Km}^{2}$ de área de estudo, equivalente a $8,2 \%$ e são constituídas por áreas de cultivo e solo exposto que ocuparam áreas originalmente de Campos Naturais. Essas áreas são caracterizadas por lavouras temporárias, horticultura e floricultura e possuem significativa dependência energética e de tecnologia (IPARDES, 2017). As áreas de solo exposto são geralmente partes "danificadas" do solo, como mostra a figura 9 ou provenientes de transição de culturas.

Figura 9 - Hemerobia média, correspondente a uma erosão em área de cultivo do município de Pinhais/PR

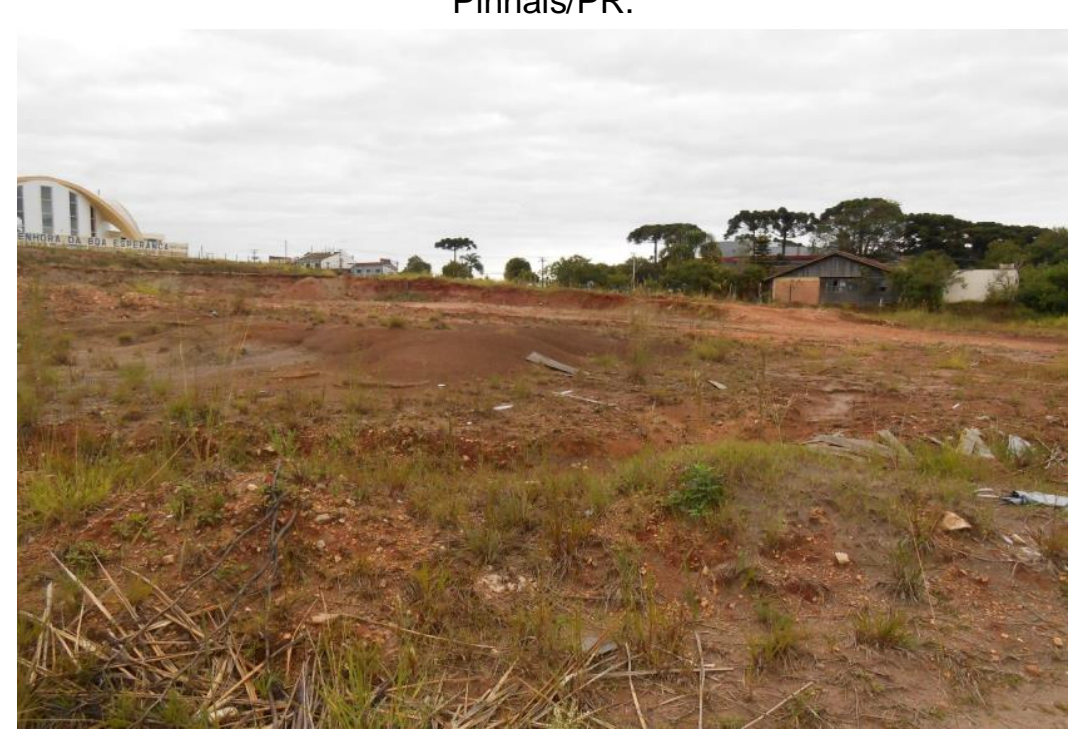

Fonte - autores, 2018. 
Dentre os problemas ocasionados pelos processos erosivos, está a questão do transporte de sedimentos para dentro dos corpos hídricos, causando o assoreamento do mesmo, o que acaba encarecendo o tratamento da água e aumentando a perda de solo, além de implicar diretamente na maior probabilidade de contaminação dos mananciais que abastecem a região, impulsionando o uso de tecnologia e o consumo de energia para o tratamento das águas.

\section{Paisagem com Hemerobia Alta}

Essa paisagem representa $5 \mathrm{Km}^{2}$ da área total do município de Pinhais e corresponde à $8,2 \%$. Caracteriza-se pela presença de edificações baixas e de pequeno porte, com a existência de jardins, bosques e demais áreas verdes em suas adjacências, constituindo-se, predominantemente, por usos residenciais (FIGURA 10).

De acordo com Valaski e Nucci (2018), a dinâmica ambiental nesse tipo de estrutura corresponde a uma infiltração média das águas pluviais, com um aumento do escoamento superficial, amplitudes térmicas médias, além de baixas taxas de emissão de poluentes na atmosfera.

Figura 10 - Hemerobia Alta, correspondente às áreas urbanizadas pouco adensadas do município de Pinhais/PR.

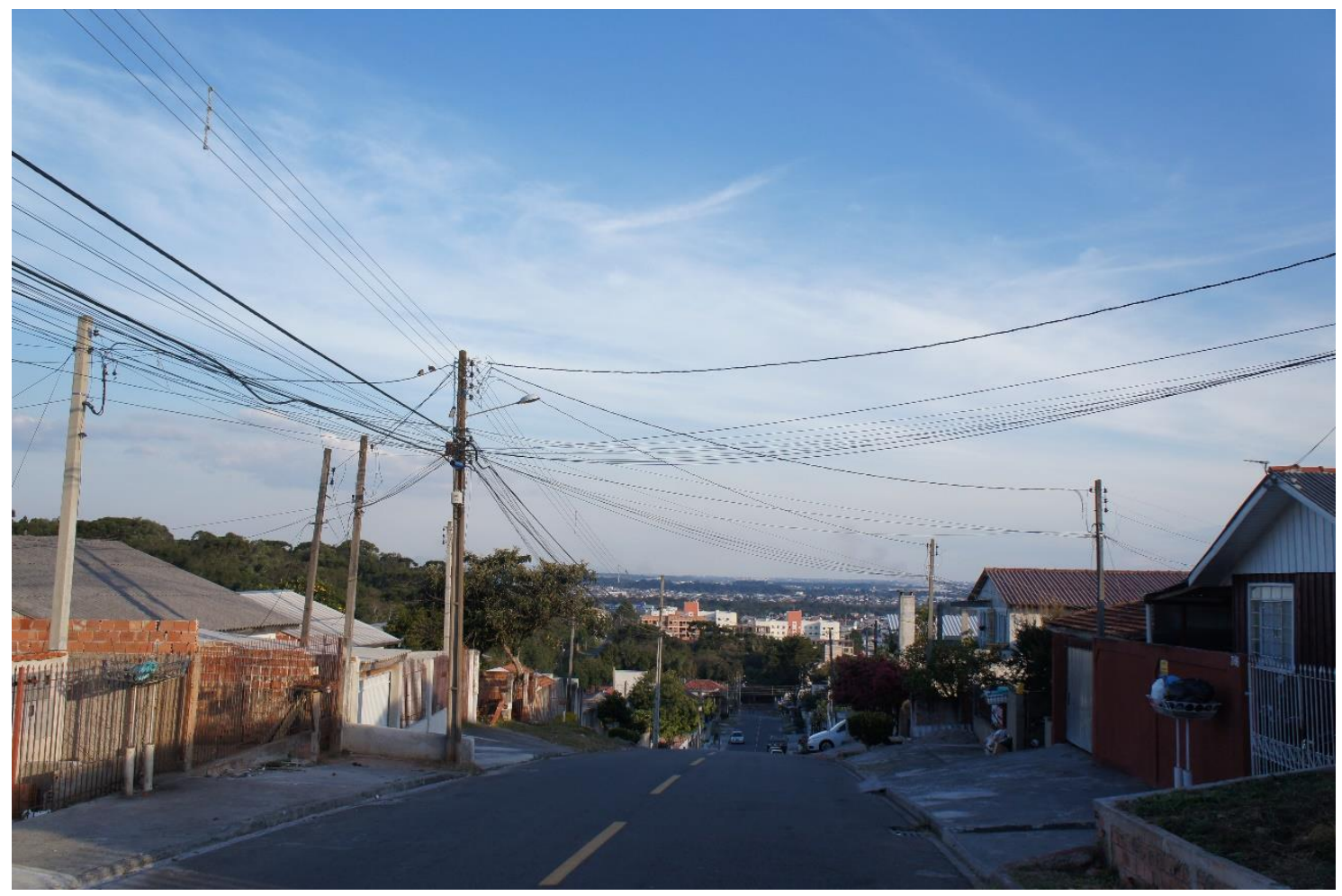

Fonte - autores, 2018.

\section{Paisagem com Hemerobia Máxima}

A paisagem com hemerobia máxima corresponde a classe com maior representatividade em relação à área total, são $25 \mathrm{~km}^{2}$, o que equivalem a $40,9 \%$ da área de estudo. Esta classe concentra-se em duas sub bacias, a do rio Iraí e do rio Palmital, nas partes oeste, sudoeste e centro do município, sendo caracterizadas pelo alto risco de inundação potencializado pela ocupação desordenada e a supressão quase que completa da vegetação. Os usos configuram-se como residencial, comercial, industrial e locais de eventos, com destaque para a indústria Moinho Rosso (figura 11), fabricante de produtos alimentícios a base de farinha de trigo. 
Figura 11 - Hemerobia máxima, correspondente à Indústria Moinho Rosso, localizado no bairro Weissópolis, em Pinhais/PR.

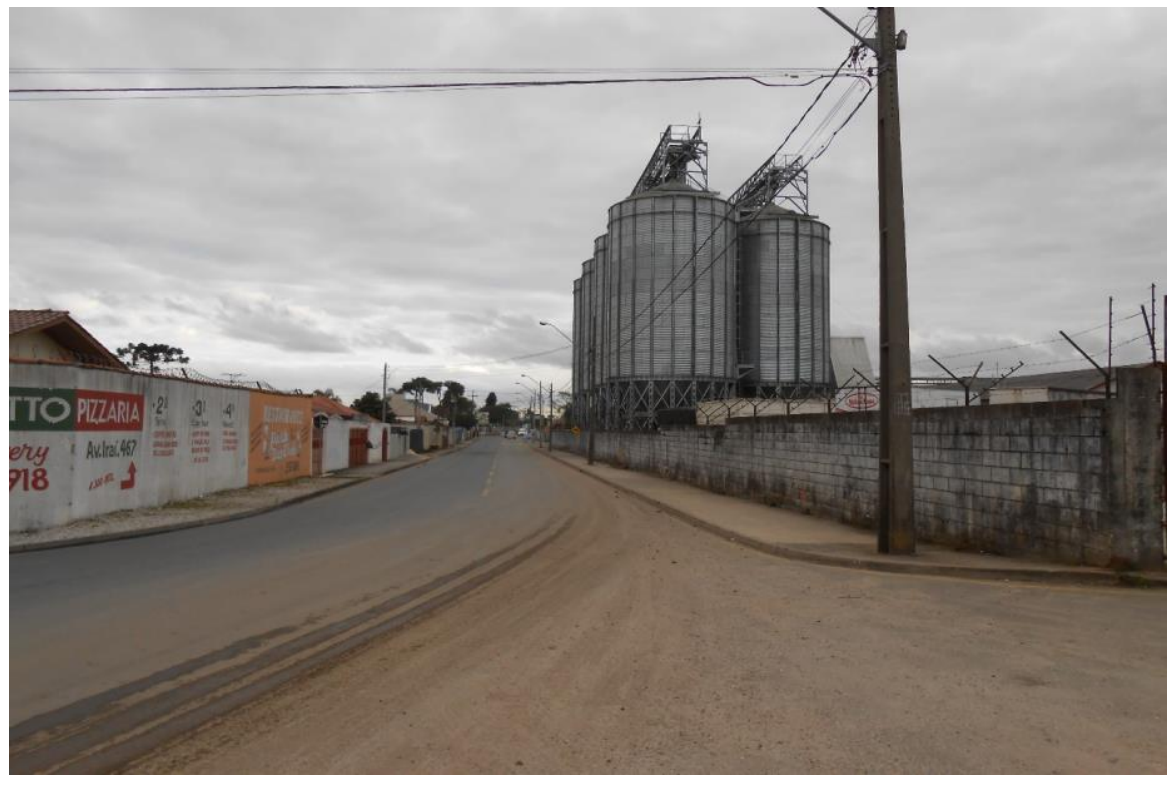

Fonte - autores, 2018.

Essa paisagem apresenta edificações concentradas, sendo identificadas algumas estruturas de maior porte, caracterizadas por grandes galpões de uso comercial e industrial, com pouca ou sem vegetação em suas áreas adjacentes, colaborando assim para o alto escoamento superficial das águas fluviais e a baixa infiltração no solo, alterando o ciclo hidrológico (VALASKI e NUCCI, 2018), acarretando também em outros problemas ambientais urbanos, como, por exemplo, na poluição sonora e visual, na limitação da biodiversidade, dentre outros.

De acordo com Bélem e Nucci (2011, p. 226) a particularidade desta classe está associada a "[...] modificação do microclima, pois por vezes a altura dos edifícios ou a grande área que ocupam modificam a dinâmica atmosférica natural. A dependência de uma manutenção intensiva e dispendiosa é total".

\section{CONSIDERAÇÕES FINAIS}

Com base na adaptação do método proposto por Belem e Nucci (2011), foi possível classificar os graus de dependência energética e tecnológica (hemerobia) do munícipio de Pinhais. A aplicação do método em escalas menores do que a originalmente proposta pelo mesmo mostrou-se eficiente quanto aos resultados alcançados,

Pinhais possui $26 \mathrm{Km}^{2}$, ou $42,7 \%$ de sua área total com hemerobia entre mínima e baixa, sendo essas consideradas as melhores classes, visto que apresentam pouca ou nenhuma dependência energética e tecnológica, apresentando um elevado grau de auto regulação das funções ecológicas em comparação as demais.

Essas paisagens estão fragmentadas nas partes norte, nordeste, leste, sudeste e centro da área de estudo, sendo caracterizadas por áreas com vegetação, corpos hídricos e áreas de campo/pasto. Nessas paisagens com mínima e baixa hemerobia, o armazenamento no solo das águas pluviais auxilia no baixo escoamento superficial, contribuindo para a regulação da vazão dos corpos hídricos, para a filtragem e, consequentemente, para a qualidade das águas, questões importantes para a função da natureza como manancial de água para abastecimento da RMC.

As demais paisagens somam $57.3 \%$, ou $35 \mathrm{Km}^{2}$ do total da área de estudo. A hemerobia máxima concentra-se nas partes oeste, sudoeste e centro de Pinhais e representa os maiores valores quantitativos em relação à área total, correspondendo a $25 \mathrm{Km}^{2}$, ou $40,9 \%$ do total da área estudada. A cobertura e o uso da terra constituem-se por áreas de urbanização adensada, com a presença de grandes edificações residenciais, comerciais e industriais, com pouca ou nenhuma vegetação em suas adjacências, necessitando alto gasto energético e tecnológico para a manutenção e regulação das funções ecológicas da paisagem. 
A aplicação do método proposto por Belem e Nucci (2011), mesmo sendo utilizado em uma escala menor que a originalmente proposta e necessitando de adaptações pontuais, demonstrou-se de fácil aplicação e entendimento, além de apresentar importantes resultados.

Considera-se, por fim, que a proposta metodológica para a avaliação da hemerobia das paisagens apresenta-se como uma importante ferramenta de compreensão geral dos processos que demandam gastos energéticos e tecnológicos e, consequentemente, que causam maior ou menor degradação na estrutura física dos ambientes urbanos e, consequentemente, nas funções ecológicas da paisagem. Neste estudo, a paisagem é entendida como um sistema complexo, ou seja, formado por vários componentes em interações orgânicas que não podem ser completamente formalizadas matematicamente (INGEGNOLI, 2002), portanto, nesta perspectiva, os estudos referentes à hemerobia, com propostas metodológicas, aplicações e discussões, apresentam-se como uma importante ferramenta de auxílio para a compreensão das dinâmicas da paisagem urbana, colaborando para o planejamento, gestão e ordenamento das cidades.

\section{AGRADECIMENTOS}

Os autores agradecem o apoio financeiro da CAPES pela concessão das bolsas de mestrado ao primeiro autor e ao Instituto LACTEC para o segundo autor e ao CNPq pela bolsa de produtividade em pesquisa ao quarto autor.

\section{REFERÊNCIAS}

BARBARA, A. D. L. S; VALASKI, S; NUCCI, J. C. Hemerobia e Planejamento da Paisagem do bairro Mossunguê, Curitiba - PR. Geografar (Programa de Pós-Graduação em Geografia - UFPR), v. 9, n. 1 , Curitiba, 2014, p. 159-179. https://doi.org/10.5380/geografar.v9i1.36540

BELEM, A. L. G.; NUCCI, J. C. Hemerobia das paisagens: conceito, classificação e aplicação no bairro Pici - Fortaleza - CE. RA'EGA 21 (2011), Curitiba: DGEOG-UFPR.

https://doi.org/10.5380/raega.v21i0.21247

BELEM, A. L. G; NUCCI, J. C. Dependência energética e tecnológica (hemerobia) do bairro Santa Felicidade, Curitiba - PR. Caminhos de Geografia (Programa de Pós-Graduação em Geografia - UFU), v. 15, n. 51, Uberlândia, 2014, p. 37-51.

CAVALHEIRO, F. Urbanização e alterações ambientais. In: SANTOS, D. G. dos; NUCCI, J.C. (Orgs.) Paisagens Geográficas: Um tributo a Felisberto Cavalheiro. 1 ed. Campo Mourão: Editora da FECILCAM, 2009. v.1. p. 65-77. (e-book). Disponível em $<$ http://www.fecilcam.br/editora/index.php?option=com_content\&task=blogcategory\&id=6\&ltemid=12> . Acesso em abril/2018.

CHEPAK, M. F. de A. Atlas Geográfico do município de Pinhais. 2008. Disponível em: <http://www.educadores.diaadia.pr.gov.br/arquivos/File/2010/mapas/atlas_comentados/pinhais_2.pdf> Acesso em: mar. 2018.

DE GROOT, R. S. Functions of nature: evaluation of nature in environmental planning, management and decision-making. Amsterdam: Wolters-Noordhoff, 1992, 315p.

FRANZ, G. A. S; CUNHA, C. L. N; GOBBI, M, F. Eutrofização em um Reservatório Destinado ao Abastecimento Público: O Caso do Reservatório do Iraí-Pr. XVII Simpósio Brasileiro de Recursos Hídricos, São Paulo, 2007.

HABER, W. Using Landscape Ecology in Planning and Management. In: ZONNEVELD, I.S.; FORMAN, R.T.T. (Eds.) Changing Landscapes: an ecological perspective. New York: Springer-Verlag, 1990, 286p. https://doi.org/10.1007/978-1-4612-3304-6 12

IBGE - Instituto Brasileiro de Geografia e Estatística. População. 2010. Disponível em: <http://www.ibge.gov.br>. Acesso em: fev. de 2018.

IBGE - Instituto Brasileiro de Geografia e Estatística. Arranjos Populacionais e Concentrações Urbanas do Brasil. 2ª ed., Rio de Janeiro, 2016.

INGEGNOLI, V. Landscape Ecology: a widening foundation. Berlin: Springer, 2002. https://doi.org/10.1007/978-3-662-04691-3 
IPARDES - Instituto Paranaense de Desenvolvimento Econômico e Social. Caderno Estatístico do Município de Pinhais. 2017. Disponível em:

<http://www.ipardes.gov.br/cadernos/MontaCadPdf1.php?Municipio=83320>. Acesso em: mar. de 2018.

JALAS, J. Hemerobe und hemerochore Pflanzenarten. Ein terminologischer Reformversuch. Acta Soc. Fauna Flora Fen. 72 (11): 1-15, 1955.

MCHARG, I. Design With Nature. New York: Back Edition, 1971, 198p.

MATEO-RODRIGUEZ, J. M.; SILVA, E. V. da; CAVALCANTI, A. P. B. Geoecologia das Paisagens: uma visão geossistêmica da análise ambiental. Fortaleza: UFC edições, 2007. 222p.

NAVEH, Z; LIEBERMAN, A. S. Landscape Ecology. Theory and Application. New York: Springer-Verlag, 1984, 105p.

NUCCI, J. C; BELEM, A. L. G; KRÖKER, R. Evolução da paisagem do bairro Santa felicidade (CuritibaPR), com base no conceito de hemerobia. Revista do Departamento de Geografia, Universidade de São Paulo, São Paulo, v. 31, 2016, p. 58-71. https://doi.org/10.11606/rdg.v31i0.104279

PANIZZA, A. de C. Como Eu Ensino Paisagem. São Paulo: Melhoramentos, 2014.

PARANÁ. DECRETO № 1.753, DE 06 DE MAIO DE 1996. Instituída a Área de Proteção Ambiental na área de manancial da bacia hidrográfica do rio Iraí, denominada APA Estadual do Iraí. Disponível em:

http://www.icmbio.gov.br/cepsul/images/stories/legislacao/Decretos/1996/dec_1753_1996_apaestadualirai pr.pdf. Acesso em: fev. de 2018.

PINHAIS. Lei Municipal no 1233, DE 30 DE SETEMBRO DE 2011. Zoneamento, o Uso e a Ocupação do Solo no Município de Pinhais. Disponível em:

$<$ http://www.pinhais.pr.gov.br/urbanismo/uploadAddress/Lei123311_Zonamento,_Uso_e_Ocupacao_do_S olo[4271].pdf>. Acesso em: fev. de 2018.

PINHAIS, PREFEITURA MUNICIPAL. Obras Públicas: Limpeza e Desassoreamento dos Rios, 2014. Disponível em: <http://www.pinhais.pr.gov.br/obras/News160content9042.shtml>. Acesso em: fev. de 2017.

PINHAIS, PREFEITURA MUNICIPAL. Plano de Habitação e Regularização Fundiária de Pinhais - PR. 2010. Disponível em: http://www.pinhais.pr.gov.br/urbanismo/FreeComponent501content6352.shtml. Acesso em: mar. de 2018.

SANTOS, R. F. dos. Planejamento ambiental: teoria e prática. São Paulo: Oficina de Textos, 2004.

SILVA, M. F; NUCCI, J. C. Hemerobia das paisagens e lei de zoneamento do bairro Capela Velha no município de Araucária - PR. Ateliê Geográfico, Goiânia-GO, v. 10, n. 2, p. 82-96, 2016. https://doi.org/10.5216/ag.v10i2.35784

SUKOPP, H. Wandel von Flora und Vegetation in Mitteleuropa unter dem Einfluss dês Menschen. Berichte uber Landwirtschaft, Bd. 50/H.1: 112-139, 1972.

TROPPMAIR, H. Biogeografia e meio ambiente. Rio Claro: edição do autor, 1989.

Walz, U; Stein, C. Indicators of hemeroby for the monitoring of landscapes in Germany. Journal for Nature Conservation, 22, 279-289, 2014. https://doi.org/10.1016/j.jnc.2014.01.007

VALASKI, Simone.; NUCCI, João. C. Estrutura e dinâmica da paisagem do município de Curitiba/PR. Subsídios para participação popular no desenvolvimento urbano. Beau Bassin: Novas Edições Acadêmicas, 2018, 144p

ZONNEVELD, I. S; FORMAN, R. T. T. Changing Landscape: an ecological perspective. New York: Springer-Verlag, 1990. https://doi.org/10.1007/978-1-4612-3304-6

Recebido em: 16/06/2018

Aceito para publicação em: 26/11/2019 